\title{
Pengaruh Ekstrak Daun Sirih dan Metode Ekstraksinya Dalam Menghambat Penyakit Antraknosa pada Cabai Pascapanen
}

\author{
Extract of Piper betle as An Inhibitor of Anthracnose Postharvest \\ Disease on Chili Pepper
}

\author{
Desi Trisnawati, Lilik Pujantoro Eko Nugroho, Efi Toding Tondok* \\ Institut Pertanian Bogor, Bogor, 16680
}

\begin{abstract}
ABSTRAK
Cabai merupakan komoditas hortikultura yang sering dibutuhkan masyarakat dalam keadaan segar. Namun demikian, ada waktu jeda yang diperlukan untuk mengantarkan cabai dari produsen (petani) ke konsumen. Selama dalam rantai pasokan tersebut, kualitas buah cabai dapat mengalami penurunan antara lain oleh adanya penyakit antraknosa yang disebabkan oleh Colletotrichum spp. Penggunaan fungisida untuk mengendalikannya sangat tidak dianjurkan karena akan meninggalkan residu yang berbahaya bagi konsumen. Alternatif yang dapat dilakukan adalah dengan pemanfaatan bahan-bahan nabati sebagai fungisida. Penelitian ini bertujuan untuk menguji manfaat ekstrak daun sirih (EDS) dalam menghambat pertumbuhan Colletotrichum acutatum pada cabai pascapanen. Penelitian dimulai dengan ekstraksi daun sirih dengan metode perebusan yang didahului pelayuan (blanching), perajangan, dan tanpa perlakuan pada daun sirih, lalu masing-masing diuji keefektifannya pada $C$. acutatum. Pengujian selanjutnya untuk menentukan konsentrasi yang efektif secara in vitro dengan cara peracunan media tumbuh $C$. acutatum. Pengujian ketiga berupa aplikasi EDS pada buah cabai dengan cara disemprot dan direndam, diamati persentase buah cabai yang terserang C. acutatum. Hasil penelitian menunjukkan bahwa metode perajangan merupakan metode ektraksi daun sirih terbaik di antara perlakuan lain, penggunaan konsentrasi EDS 10\% merupakan konsentrasi paling efektif dalam menghambat pertumbuhan $C$. acutatum, perlakuan penyemprotan menggunakan EDS $10 \%$ paling efektif menghambat terjadinya penyakit antraknosa.
\end{abstract}

Kata kunci: Colletotrichum acutatum, ekstraksi, fungisida nabati, in vitro, in vivo.

\begin{abstract}
Chili is a horticultural commodity that mostly needed by consumers in the fresh condition. However, there is an interval of time needed to deliver it from producers (farmers) to consumers. During the supply chain, deterioration of the quality of chilli fruit can occur by the presence of anthracnose disease caused by Colletotrichum spp. The use of syntetic fungicides to control anthracnose disease is not recommended because it will leave residues that are harmful to consumers. The alternative that can be done is to use botanical pesticides as fungicides. The aim of this research is to study the potential of Piper betle leaves extract (PLE) in inhibiting the development of the antracnose disease caused by Colletotrichum acutatum on the chili during storage. The sequences of this research were strarted with production of PLE by boiling method which was preceded by blanching, chopping, and without treatment of betel leaves, then bioassay of betel extract by measuring the diameter of fungus growth on PDA+ PLE. The third test was application of PLE on fresh chili fruits by spraying and soaking, continued by observed the antracnose

*Alamat penulis korespondensi: Departemen Proteksi Tanaman, Fakultas Pertanian, Institut Pertanian Bogor, Jalan Kamper, Kampus IPB Dramaga, Bogor, 16680.

Tel: 0251-8629364,Faks: 0251-8629362,Surel: ettondok@apps.ipb.ac.id
\end{abstract}


insidence on chili during storage time (21 days). The results showed that the chopping method was the best betel leaf extraction method among other treatments, the use of 10\% PLE concentration was the most effective concentration in inhibiting the growth of $C$. acutatum in vitro, spraying treatment using $10 \%$ EDS was the most effective in inhibited the insidence of anthracnose disease.

Key words: botanical fungicide, Colletotrichum acutatum, extraction, in vitro, in vivo.

\section{PENDAHULUAN}

Cabai merah (Capsicum annuum) merupakan salah satu komoditas yang berperan penting sebagai bumbu pelengkap masakan di Indonesia. Komoditas ini terdiri dari beberapa varietas diantaranya cabai merah besar dan cabai rawit. Data produksi cabai merah di Indonesia dari tahun 2011 sampai 2017 memiliki pola peningkatan, kecuali tahun 2015 yang mengalami penurunan sebesar $2.59 \%$ dibandingkan tahun 2014, kenaikan produksi cabai merah pada tahun 2017 adalah 15.37\% (BPS 2017). Permintaan yang tinggi terhadap komoditas cabai merah di Indonesia mendorong beberapa produsen untuk menyediakan dalam kondisi baik, yaitu segar dan tidak terdapat kerusakan akibat infeksi patogen atau serangan hama.

Infeksi Colletotrichum spp. penyebab penyakit antraknosamenjadi salah satu masalah terbesar dalam pengelolaan pascapanen cabai merah. Kondisi pengelolaan pascapanen cabai di Indonesia umumnya masih belum optimal dilakukan. Hal tersebut mendorong dilakukan penelitian terkait teknologi pascapanen cabai merah dengan menggunakan bahan nabati yang lebih aman terhadap lingkungan dan manusia. Bahan nabati yang berpotensi digunakan untuk menekan perkembangan penyakit antraknosa cabai merah pada pascapanen ialah daun sirih. Daun sirih (Piper betle) merupakan Famili Piperaceae yang memiliki kandungan anticendawan berupa minyak atsiri (isocugenol, limonene, dan kariefilena) (Hertiana dan Purwati 2002). Senyawa-senyawa tersebut bisa didapatkan dari proses ekstraksi daun sirih.

Penelitian ini bertujuan untuk menentukan metode ekstraksi daun sirih yang paling baik dalam menghambat pertumbuhan Colletotrichum acutatum, menentukan konsentrasi ekstrak daun sirih (EDS) yang efektif dalam menghambat pertumbuhan $C$. acutatum, serta menentukan teknik aplikasi EDS yang dapat menekan insidendsi penyakit antraknosa pada cabai selama penyimpanan.

\section{BAHAN DAN METODE}

Daun sirih diperoleh dari pertanaman sirih di Lampung, dengan kriteria daun sirih segar berwarna hijau, tingkat ketuaan sedang (daun terletak di bagian tengah tangkai tanaman), bentuk daun utuh (tidak malformasi, tidak termakan serangga dan tidak terserang penyakit). Daun sirih dipetik pada pagi hari kemudian dikemas dengan menggunakan kardus dan dikirim secepat mungkin menuju laboratorium selama 15 jam.

Isolat cendawan yang digunakan pada penelitian ini ialah C. acutatum SMG 136 milik Klinik Tanaman Departemen Proteksi Tanaman, Institut Pertanian Bogor. Isolat cendawan diremajakan pada medium agaragar dekstrosa kentang (ADK) dan diinkubasi selama 5-7 hari.

Buah cabai yang digunakan dalam penelitian ini adalah buah cabai merah keriting yang diperoleh dari pertanaman cabai di Ciawi, Jawa Barat. Cabai dipilih dengan kriteria cabai matang, berwarna merah seragam, panen pertama dilakukan setelah pertanaman berbuah merah lebih dari 60 persen, terlihat sehat (tidak ada gejala serangan patogen).

Peralatan yang digunakan dalam penelitian ini adalah pisau, pinset, penggaris, timbangan digital, cawan petri, erlenmeyer, lemari asam, autoklaf, jangka sorong, mikroskop, rheometer tipe CR-300DX, perangkat image prosessing.

\section{Ekstrasi Daun Sirih dan Uji Pendahuluan}

Daun sirih dicuci bersih agar tidak ada kotoran dan kontaminan lain. Sebelum 
diekstraksi dengan metode perebusan, daun sirih disiapkan dengan 3 perlakuan, yaitu daun sirih segar tanpa persiapan (kontrol), dilayukan (blanching), dan dirajang. Masingmasing daun sirih tersebut direbus dalam air dengan perbandingan daun sirih dan air ialah 1:1 selama 1 jam (Achmad dan Suryana 2009). Hasil rebusan disaring dan disterilkan menggunakan autoklaf pada suhu $121^{\circ} \mathrm{C}$ untuk mendapatkan ekstrak daun sirih steril (EDS). Selanjutnya konsentrasi EDS ditentukan menggunakan rumus sebagai berikut:

$$
\operatorname{EDS}(\%)=\frac{\mathrm{e}}{\mathrm{e}+\mathrm{a}} \times 100 \% \text {, dengan }
$$

e, volume ekstrak daun sirih (EDS) yang diambil dari EDS hasil ekstraksi (mL); dan a, volume media yang ditambahkan $(\mathrm{mL})$.

Ekstrak daun sirih dengan konsentrasi $0 \% \quad$ (kontrol); $0.5 \% ; \quad 1 \% ; \quad 1.5 \%$; dan $2 \%$ dicampurkan dalam medium ADK. Selanjutnya koloni $C$. acutatum berdiameter $7 \mathrm{~mm}$ diambil dari biakan murni berumur 10 hari dan diletakkan pada medium ADK yang telah dicampur dengan EDS lalu diinkubasi pada suhu $27{ }^{\circ} \mathrm{C} \pm 2$ di ruang tertutup. Pengamatan diameter pertumbuhan koloni $C$. acutatum dilakukan setiap hari hingga hari ke21. Percobaan disusun dalam rancangan acak lengkap faktorial dengan 3 kali ulangan.

Data dianalisis menggunakan analysis of variance (ANOVA) dan diuji lanjut dengan uji Tukey pada taraf nyata $5 \%$ menggunakan Minitab 16. Ekstrak daun sirih yang diperoleh dengan metode esktraksi dan memberikan hasil penekanan terbaik digunakan pada uji selanjutnya.

\section{Penentuan Konsentrasi Ekstrak Daun Sirih}

Ekstrak daun sirih yang diperoleh dari perlakuan perajangan memberikan hasil terbaik pada pengujian metode ekstraksi sehingga penyiapan bahan dengan metode ini digunakan pada penelitian selanjutnya. Pada uji pendahuluan digunakan konsentrasi rendah dan belum memberikan hasil yang baik sehingga pada uji selanjutnya konsentrasi dinaikkan untuk menentukan konsentrasi EDS paling efektif dalam menghambat pertumbuhan C. acutatum. Faktor utama pada penelitian ini ialah perbandingan konsentrasi EDS, yaitu $0 \%$ (kontrol), 3\%, 5\%, 10\%, 15\%, 20\%.

Prosedur penelitian pada tahap ini sama dengan penelitian sebelumnya dengan dua ulangan. Pada tahap ini dicari konsentrasi yang dianggap paling efektif untuk uji lanjut lanjutan dengan konsentrasi yang lebih kecil sebagai faktor yaitu konsentrasi $0 \%$ (kontrol), $5 \%, 6 \%, 7 \%, 8 \%, 9 \%$, dan 10\%. Metode pengamatan pertumbuhan $C$. acutatum dilakukan seperti pada penelitian pertama. Penelitian disusun dalam rancangan acak lengkap dengan lima ulangan. Data dianalisis menggunakan ANOVA dan diuji lanjut dengan uji Tukey dengan taraf nyata 5\% menggunakan Minitab 16. Hasil penentuan konsentrasi EDS paling efektif digunakan pada pengujian aplikasi EDS secara in vivo.

\section{Aplikasi Ekstrak Daun Sirih Secara in Vivo}

Aplikasi EDS secara in vivo dilakukan pada buah cabai. Buah cabai dicuci bersih agar bebas dari kotoran, kontaminan, dan pestisida. Cabai yang sudah bersih diberi perlakuan EDS $10 \%$, perlakuan terdiri atas 3 ulangan, tiap ulangan terdiri dari 50 buah cabai. Susunan perlakuan ialah tanpa pemberian daun sirih (kontrol), penyemprotan, perendaman 10 menit, perendaman 15 menit, dan perendaman 20 menit. Cabai yang telah diberi perlakuan ditiriskan dan disimpan pada suhu ruangan $\left(27{ }^{\circ} \mathrm{C} \pm 2\right.$ ) untuk selanjutnya diamati. Pengamatan dilakukan setiap hari dengan melihat ada tidaknya bercak hitam konsentris sebagai gejala penyakit antraknosa. Jumlah cabai yang bergejala antraknosa (sampai hari ke-9) dihitung. Persentase cabai yang tersinfeksi antraknosa dihitung dengan rumus menurut Bill et al. 2014:

Insidensi penyakit $=\frac{\mathrm{n}}{\mathrm{N}} \times 100 \%$, dengan

n, Jumlah cabai terserang antraknosa; dan N, Jumlah populasi cabai.

Penelitian disusun menggunakan rancangan acak lengkap dan dianalisis dengan ANOVA. Hasil yang berbeda nyata diuji lanjut Tukey dengan taraf nyata 5\% menggunakan Minitab 16. 


\section{HASIL}

Penelitian pertama bertujuan untuk menentukan metode ekstraksi daun sirih yang baik dalam menghambat pertumbuhan C. acutatum. Hasil analisis sidik ragam (Gambar 1) menunjukkan adanya perbedaan nyata antara daun sirih utuh dengan perlakuan perajangan pada hari ke-15. Ekstrak daun sirih hasil perajangan mampu menekan pertumbuhan $C$. acutatum dengan diameter paling rendah, yaitu sebesar $26.62 \mathrm{~mm}$ pada konsentrasi $1 \%$.

Pada penelitian tahap kedua, C. acutatum tidak tumbuh pada konsentrasi EDS 10\% namun masih tumbuh pada konsentrasi EDS 5\% (Gambar 2). Uji lanjut menunjukkan bahwa konsentrasi EDS 9\% dan 10\% mampu menghambat pertumbuhan $C$. acutatum hingga hari ke 8 (Gambar 3). Pada hari ke-21, pertumbuhan koloni $C$. acutatum pada EDS 9\% dan $10 \%$ terlihat bebeda nyata dengan perlakuan lainnya (Gambar 4), tetapi untuk aplikasi EDS secara in vivo dipilih EDS 10\% karena pada konsentrasi tersebut $C$. acutatum tidak tumbuh.

Hasilpenelitianin vivo menunjukkanbahwa aplikasi EDS $10 \%$ pada buah cabai mampu menekan insidensi penyakit antraknosa selama penyimpanan. Dari percobaan ini terlihat bahwa cara aplikasi penyemprotan lebih baik (46.63\%) dan berbeda nyata dalam menekan insidensi penyakit antraknosa dibandingkan dengan kontrol. Perlakuan dengan metode perendaman tidak memberikan hasil yang konsisten, perendaman selama 10 dan 20 menit berbeda nyata dengan kontrol, tetapi perendaman selama 15 menit tidak berbeda nyata dengan kontrol (Gambar 5).

\section{PEMBAHASAN}

Penyiapan bahan daun sirih sebelum diekstraksi dengan cara perajangan memberikan hasil terbaik dalam menghambat pertumbuhan C. acutatum. Metode perajangan merupakan proses yang dapat mempermudah keluarnya senyawa fenol yang terkandung di dalam daun sirih sehingga mampu menekan pertumbuhan C. acutatum dengan diameter paling rendah. Hal ini sejalan dengan penelitian Sudrajad (2004) yang menyatakan bahwa semakin tipis irisan simplisia, akan menyebabkan minyak atsiri yang terkandung di dalamnya mudah menguap dan akan semakin besar kandungan minyak atsiri yang dihasilkan. Kelemahan

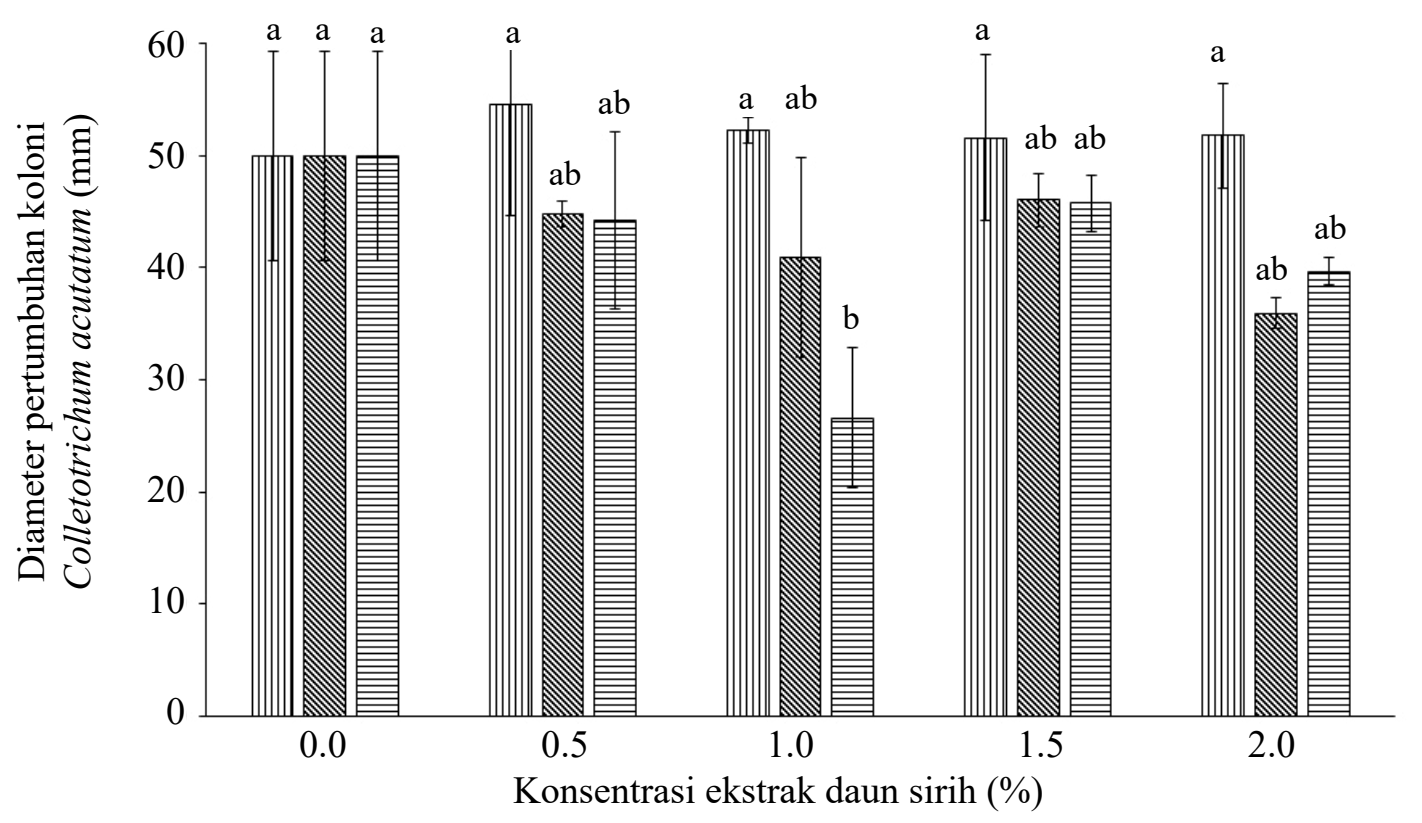

Gambar 1 Pertumbuhan koloni Colletotrichum acutatum pada masing-masing metode ekstraksi daun sirih saat 15 hari setelah perlakuan (hsp). Huruf yang sama menunjukkan tidak ada perbedaan yang nyata. IIII, Daun sirih segar; $\mathbb{N}$, Pelayuan (blancing); dan $\equiv$, Perajangan. 


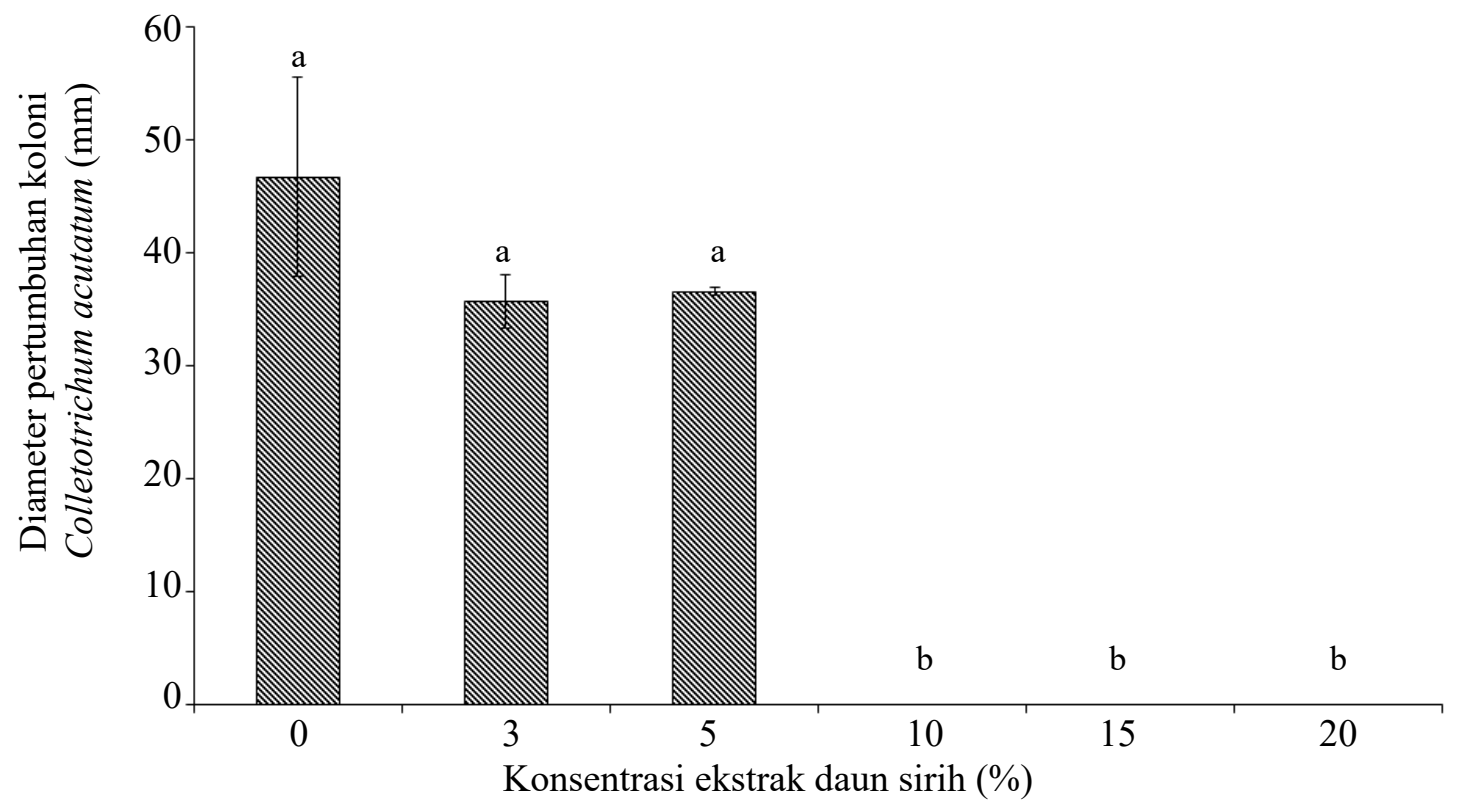

Gambar 2 Pertumbuhan koloni Colletotrichum acutatum pada uji pendahuluan beberapa konsentrasi ekstrak daun sirih saat $21 \mathrm{hsp}$. Huruf yang sama menunjukkan tidak berbeda nyata.

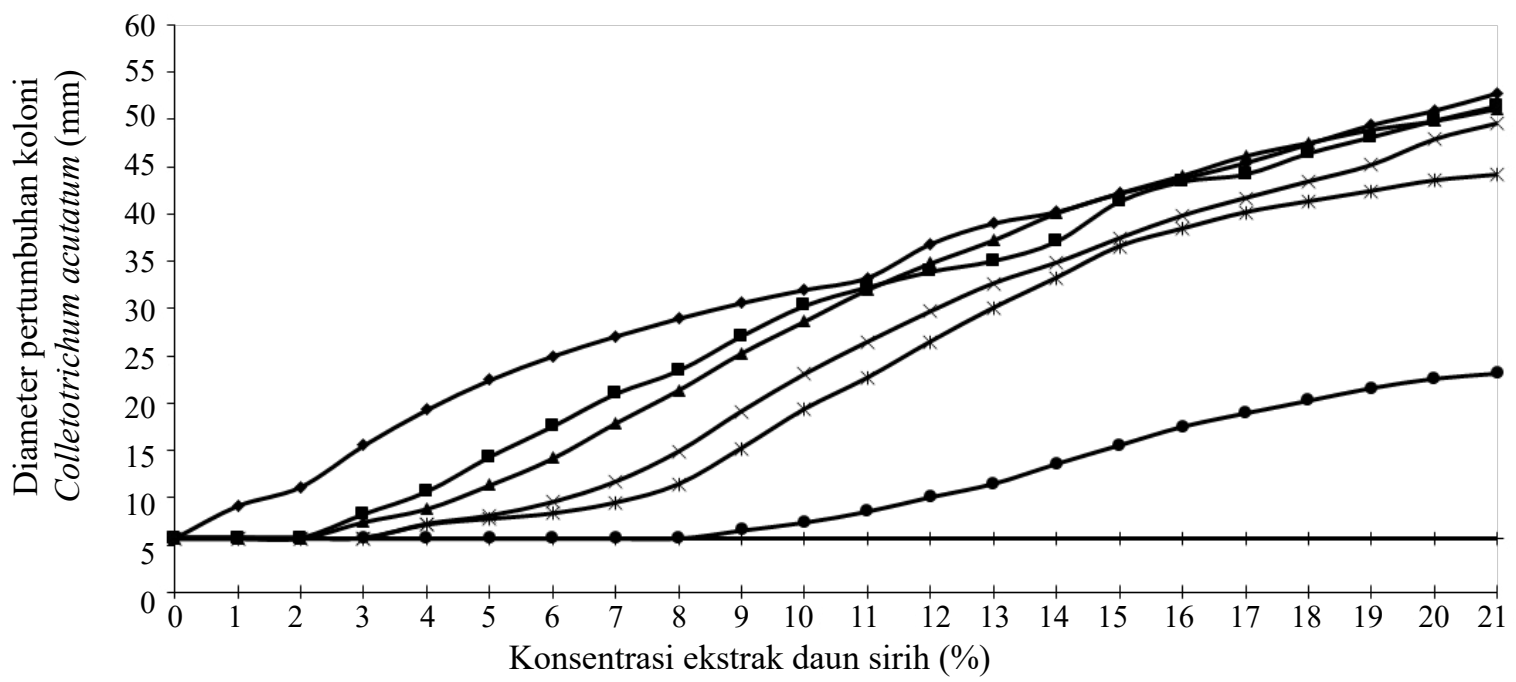

Gambar 3 Pertumbuhan koloni C. acutatum pada medium ADK yang mengandung konsentrasi

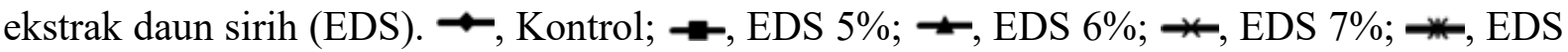
$8 \%$; $\rightarrow$, EDS 9\%; dan $\longrightarrow$, EDS 10\%.

pada penelitian pertama ialah tidak dilakukan analisis senyawa fenol yang terkandung dalam EDS sehingga tidak diketahui pasti berapa banyak kandungan senyawa fenol pada masing-masing perlakuan.

Konsentrasi EDS 10\% menunjukkan tingkat efikasi paling tinggi, yaitu $100 \%$ dalam menghambat pertumbuhan $C$. acutatum secara in-vitro. Ekstrak daun sirih diketahui dapat menghambat pertumbuhan Rhizoctonia sp. dengan cara merusak jaringan dan mengakibatkan kerusakan struktur hifa cendawan (Achmad dan Suryana 2009). Salah satu senyawa kimia yang dapat menghambat infeksi patogen seperti $C$. acutatum ialah senyawa fenolik yang dapat dioksidasi oleh peroksidase (Syukur et al. 2009). Peningkatan aktivitas enzimperoksidase akan meningkatkan produksi toksin bagi patogen yang berpotensi dapat mencegah perkecambahan konidia cendawan (Petkovsek et al. 2013) sehingga meningkatkan ketahanan terhadap infeksi patogen. Berbeda halnya dengan pengujian pada medium ADK, EDS yang diaplikasikan 


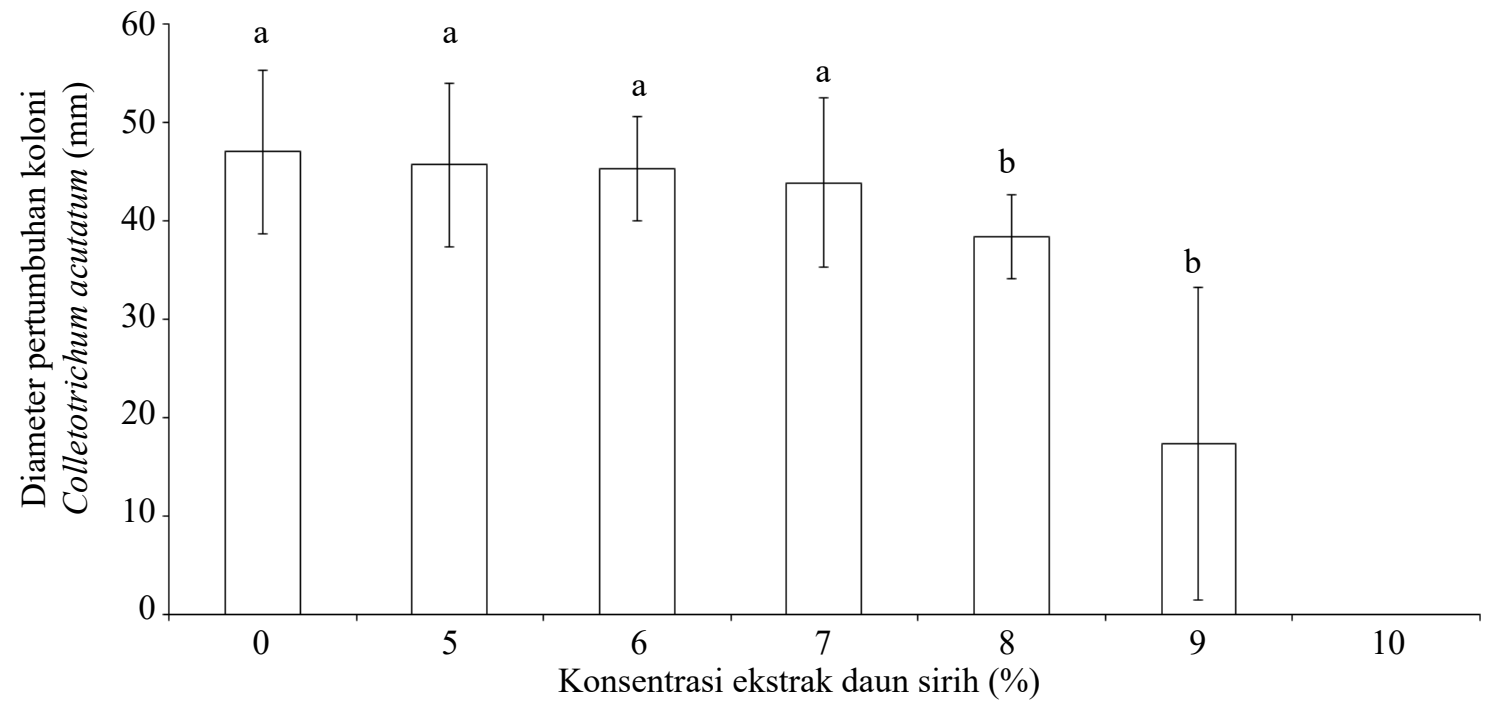

Gambar 4 Pertumbuhan koloni $C$. acutatum pada masing-masing konsentrasi uji ekstrak daun sirih saat $21 \mathrm{hsp}$. Huruf yang sama menunjukkan tidak ada perbedaan yang nyata.

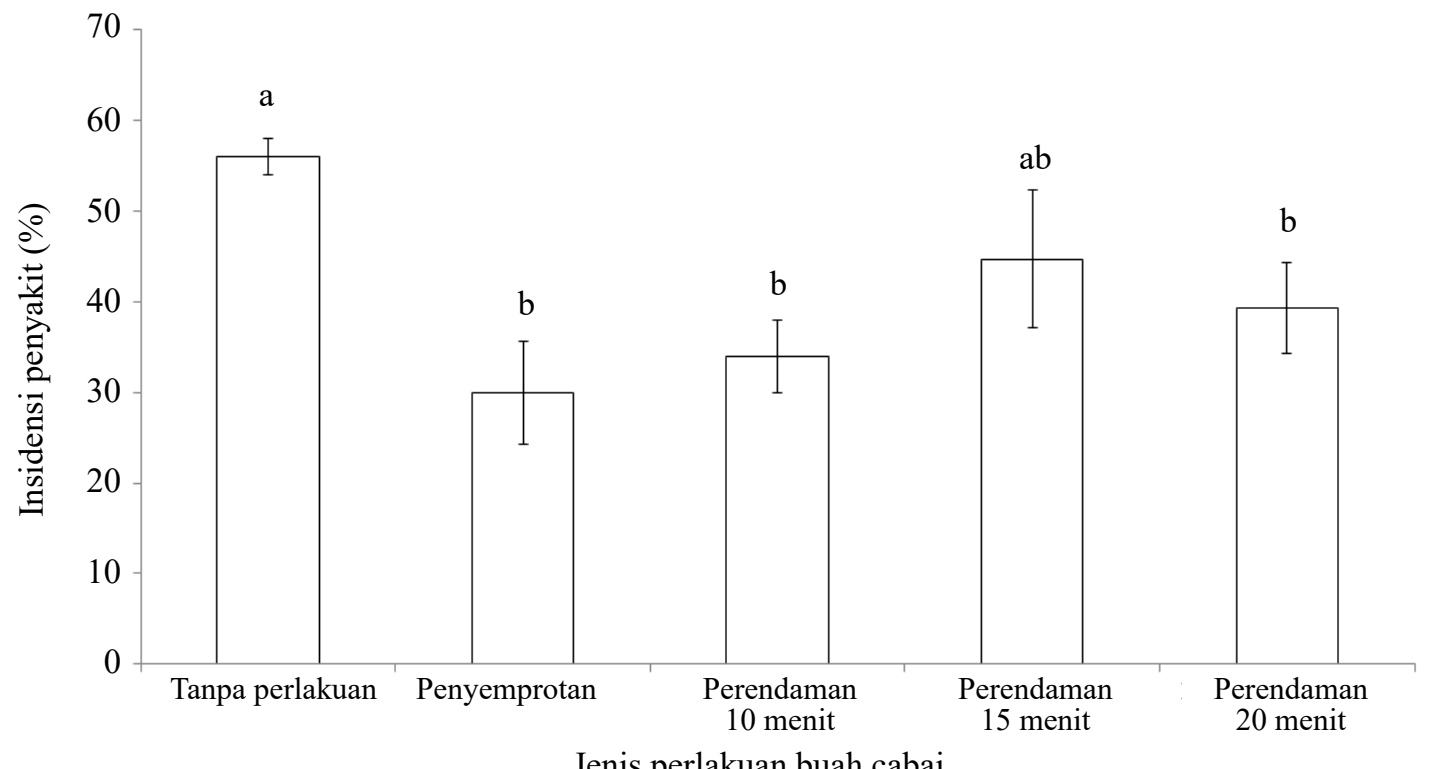

Gambar 5 Insidensi penyakit antraknosa pada uji in vivo saat 9 hsp. Huruf yang sama menunjukkan tidak ada perbedaan yang nyata

pada cabai belum menunjukkan penghambatan insidensi penyakit yang efektif. Hal tersebut diduga karena penyakit antraknosa yang bersifat laten sehingga perlu konsentrasi yang lebih tinggi dan bersifat sistemik untuk menghambat infeksi patogen yang berada di dalam jaringan. Penyemprotan EDS 10\% menunjukkan tingkat efikasi yang paling tinggi dan berbeda nyata dengan kontrol, tetapi tidak berbeda nyata dengan perlakuan perendaman. Hal tersebut diduga berkaitan dengan ketebalan lapisan lilin pada permukaan buah yang menyebabkan EDS berbasis air tidak meresap ke dalam cabai dan hanya melapisi bagian luar cabai sehingga perlakuan semprot dan perendaman tidak menunjukkan adanya perbedaan yang nyata.

Tanaman sirih merupakan tanaman yang umum dikenal masyarakat Indonesia, mudah didapat, sudah dikenal banyak manfaatnya. Ekstraksi dengan cara dirajang kemudian direbus merupakan cara yang mudah ditiru dan diulang oleh calon pengguna. Selain itu, sebagai alternatif pengganti fungisida sintetik, 
ekstrak daun sirih ramah lingkungan dan aman bagi konsumen sehingga dapat dimanfaatkan sebagai edible coating. Hasil penelitian lanjutan (unpublished) dari penelitian ini juga didapatkan bahwa perlakuan ekstrak daun sirih tidak mempengaruhi kualitas cabai, seperti warna, aroma, tekstur dan tanpa kehilangan berat cabai. Kelemahan pemanfaatan bahan nabati secara umum ialah tidak dapat menstandardisasi konsentrasi yang digunakan.

\section{DAFTAR PUSTAKA}

Achmad A, Suryana I. 2009. Pengujian aktivitas ekstrak daun sirih (Piper betle Linn.) terhadap Rhizoctonia sp. secara in vitro. Bul Littro. 20(1):92-98.

Bill M, Sivakumar D, Korsten L, Thompson AK. 2014. The efficacy of combined application of edible coatings and thyme oil in inducing resistance components in avocado (Persea americana Mill.) against anthracnose during postharvest storage. J Crop Protection. 64(2014):159167. DOI: https://doi.org/10.1016/j. cropro.2014.06.015.

[BPS] Badan Pusat Statistik. 2017. Statistik Tanaman Sayuran dan Buah-Buahan Semusim Indonesia. [diakses 2019
Desember 22]. Tersedia pada http://www. bps.go.id

Hertiana T, Purwati. 2002. Minyak Atsiri Hasil Destilasi Ekstrak Etanol Daun Sirih (Piper betle L.) beberapa Daerah di Yogyakarta. Yogyakarta (ID): Yogyakarta.

Petkovsek MM, Schmitzer V, Jakopic J, Cunja V, Veberic R, Munda A, Stampar F. 2013. Phenolic compounds as defence response of pepper fruits to Colletotrichum coccodes. J Physiol Mol Plant Path. 84(2013):138145. DOI: https://doi.org/10.1016/j. pmpp.2013.09.003.

Sudrajad H. (2004). Pengaruh ketebalan irisan dan lama perebusan (blanching) terhadap gambaran makroskopis dan kadar minyak atsiri simplisia dringo (Acorus calamus L.). Media Penelitian dan Pengembangan Kesehatan. 14(4):41-44.

Syukur M, Sujiprihati S, Koswara J, Widodo. 2009. Pewarisan ketahanan cabai (Capsicum annuum L.) terhadap antraknosa yang disebabkan oleh Colletotrichum acutatum. Bul Agron. 37(3):233-239.

Yoon JB. 2003. Identification of genetic resources, interspecific hybridization, and inheritance analysis for breeding pepper (Capsicum annuum) resistant to anthracnose. [Disertasi] Seoul: Seoul National University. 